\title{
INFLUÊNCIA DO TAMANHO DA SEMENTE NA QUALIDADE FISIOLÓGICA E NA PRODUTIVIDADE DA CULTURA DA SOJA ${ }^{1}$
}

\author{
GILDA PIZZOLANTE DE PÁDUA², ROBERTO KAZUHIKO ZITO³, \\ NEYLSON EUSTÁQUIO ARANTES ${ }^{4}$, JOSÉ DE BARROS FRANÇA NETO5
}

\begin{abstract}
RESUMO - O tamanho da semente é uma característica cujos efeitos vêm sendo estudados por diversos autores, considerando os mais diferentes componentes do desempenho tanto da semente como da planta dela resultante. Para avaliar os efeitos do tamanho de semente sobre o crescimento inicial das plantas, a produtividade e a qualidade fisiológica foram testadas três cultivares de soja, BRSMG 752S, BRSMG 790A e BRSMG 750SRR originadas de três tamanhos de semente (peneiras 4,0 $\mathrm{mm}, 5,0 \mathrm{~mm}$ e 6,0 mm). A semeadura foi efetuada em 06/12/2007 em plantio direto e o desbaste aos 21 dias após a semeadura, deixando-se treze plantas por metro. A colheita manual foi realizada em 11/04/08. Após a colheita, as sementes foram classificadas em três tamanhos, usando-se peneiras manuais de $6,0 \mathrm{~mm}, 6,5 \mathrm{~mm}$ e 7,0 $\mathrm{mm}$. O delineamento experimental foi em blocos ao acaso para o experimento de campo e inteiramente casualizado para as análises de laboratório, ambos em esquema fatorial 3 (cultivar) x 3 (peneira), com quatro repetições. Os dados obtidos foram submetidos à análise de variância pelo teste $\mathrm{F}$ e as médias foram comparadas pelo teste de Tukey a $5 \%$ de probabilidade. Para as avaliações de campo, foram determinadas altura de plantas e produtividade. No laboratório, os tratamentos foram avaliados pelos testes de germinação e de vigor (envelhecimento acelerado, classificação do vigor da plântula, comprimento e massa seca de raiz). Foi verificado que sementes menores (peneira 4,0 $\mathrm{mm}$ ) produzem plantas com menor altura na colheita e menor produtividade, em relação às sementes maiores (peneira $6,0 \mathrm{~mm}$ ). As sementes classificadas em diferentes tamanhos apresentam diferenças em qualidade fisiológica. Sementes maiores (peneira 7,0 mm) apresentam maiores porcentagens de germinação e de vigor.
\end{abstract}

Termos para indexação: Glycine max, peneira, viabilidade, vigor.

\section{INFLUENCE OF SEED SIZE ON PHYSIOLOGICAL SEED QUALITY AND SOYBEAN YIELD}

\begin{abstract}
Seed size has received special attention by researchers, who have studied aspects related to seed performance and the resulting plant. The objectives of this study were to evaluate the effects of seed size on initial plant growth, grain yield and the physiological seed quality of soybeans by testing seeds of three cultivars (BRSMG 752S, BRSMG 790A and BRSMG 750SRR), graded into three sizes $(4.0 \mathrm{~mm}, 5.0 \mathrm{~mm}$ and $6.0 \mathrm{~mm})$. No-till planting was done on December $6^{\text {th }}, 2007$ and the plants thinned 21 days after emergence to 13 plants per meter. Harvesting and seed threshing were done manually on April $11^{\text {th }}, 2008$. After harvesting, seeds were manually graded into three sizes by using round perforation screens of $6.0 \mathrm{~mm}, 6.5 \mathrm{~mm}$ and $7.0 \mathrm{~mm}$. The field trials were set up in a
\end{abstract}

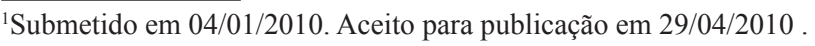

${ }^{2}$ Eng. Agr., D. Sc. Pesquisador Embrapa/EPAMIG, Caixa Postal 311, CEP 38.001-970, Uberaba/MG, gpadua@epamiguberaba.com.br.

${ }^{3}$ Eng. Agr., D. Sc. Pesquisador EPAMIG, Caixa P. 311, CEP 38.001-970, Uberaba/MG, zito@epamig.br.
}

${ }^{4}$ Eng. Agr., D. Sc. Fundação Triângulo, Caixa Postal 110, CEP 38.001-970, Uberaba/MG, neylson.arante@yahoo.com.br

${ }^{5}$ Eng. Agr., Ph D. Pesquisador Embrapa Soja, Caixa Postal, 231, CEP: 86.001-970, Londrina/PR, jbfranca@enpso.embrapa.br. 
completely randomized block design and the laboratory analyses followed a completely randomized design, both having a factorial of 3 cultivars x 3 seed sizes and four replicates. Data were submitted to analysis of variance by the $\mathrm{F}$ test and means were compared by the Tukey test at the $5 \%$ probability level. The analyzed field parameters were plant height and grain yield (kg.ha- ${ }^{-1}$ at $13 \%$ moisture) and the laboratory parameters measured were seed germination and vigor, measured by accelerated ageing, classification of seed vigor, seedling length and tests for seedling dry mass. Small seeds (4.0 $\mathrm{mm}$ ) resulted in shorter plants at harvest with a lower grain yield potential when compared to large seeds $(6.0 \mathrm{~mm})$. Physiological seed quality varied among the different sizes of the harvested seeds: best performance was observed with large seeds $(7.0 \mathrm{~mm})$ for the three cultivars. The effect of seed size on vigor was significant since large seeds $(7.0 \mathrm{~mm})$ had the highest vigor.

Index terms: Glycine max, screen, viability, vigor.

\section{INTRODUÇÃO}

A qualidade fisiológica das sementes, representada pela viabilidade e vigor, pode influenciar diretamente muitos aspectos do desempenho, como, por exemplo, a taxa de emergência e a emergência total, sendo também o tamanho de semente outro componente da qualidade que vem sendo avaliado para muitas espécies.

Sementes de alto vigor apresentam maior velocidade nos processos metabólicos, propiciando emissão mais rápida e uniforme da raiz primária no processo de germinação e maior taxa de crescimento, produzindo plântulas com maior tamanho inicial (Schuch et al., 1999; MUNIZZI et al, 2010).

A classificação da semente de soja é realizada há vários anos no Brasil; essa é uma técnica importante uma vez que a padronização por tamanho das sementes resulta num incremento da precisão de semeadura, o que facilita a obtenção da população de plantas desejada (Krzyzanowski et al., 1991).

Em soja, Vanzolini e Carvalho (2002) verificaram que as sementes mais vigorosas produziram maior comprimento da raiz primária e maior comprimento total das plântulas. Kolchinski et al. (2006) constataram que plantas de soja provenientes de sementes de alto vigor apresentaram maior área foliar e que o alto vigor das sementes proporciona maior taxa de crescimento a partir dos 21 dias após emergência. Em condições de campo, Schuch (1999) observou que as sementes de alto vigor de aveia preta produziram plantas com maiores produções de matéria seca, área foliar e taxa de crescimento, no período inicial da cultura. $\mathrm{O}$ crescimento inicial precoce pode resultar em maior captura de luz pelas folhas, possibilitando que o índice de área foliar máximo seja atingido mais rapidamente (Siddique et al., 1990).

Segundo TeKrony e Egli (1991), as estruturas da semente são importantes somente para o crescimento inicial da plântula, no período imediato após a emergência, devido a maioria dos tecidos da planta envolvidos na produção de matéria seca serem formados após a emergência da plântula. No entanto, Khah et al. (1989) observaram sob condições não competitivas, que diferenças no vigor das sementes de trigo resultaram em diferenças na taxa de crescimento relativo até sete semanas após a emergência e constataram que aqueles efeitos refletiram em estádios posteriores do desenvolvimento, em que as plantas provenientes das sementes com alta qualidade fisiológica produziram maior rendimento final de grãos.

As sementes de maior tamanho ou aquelas que apresentam maior densidade são aquelas que possuem, normalmente, embriões bem formados e com maiores quantidades de reservas, sendo potencialmente as mais vigorosas (Carvalho e Nakagawa, 2000). A maior quantidade de reserva aumenta a probabilidade de sucesso no estabelecimento da plântula (Haig e Westoby, 1991), pois permite a sobrevivência por maior tempo em condições ambientais desfavoráveis. No entanto, estudos relacionados com sementes de milho e soja demonstraram que o peso e o tamanho das sementes não influenciaram os resultados de testes conduzidos em laboratório e desempenho das plantas no campo (Silva e Marcos Filho, 1982; Martins et al., 1997 e Lima e Carmona, 1999).

Já TeKrony e Egli (1991) ressaltaram que sementes de alto vigor atuam aparentemente em fases anteriores ao crescimento da plântula e estão frequentemente associadas com o aumento da taxa de emergência e no estabelecimento do estande. Quando sementes de baixo vigor produzem populações de plantas que são menores que a necessária para um rendimento máximo, as reduções em rendimento podem estar indiretamente relacionadas com o vigor das sementes.

Neste contexto, pesquisas têm sido feitas para avaliar o vigor das sementes, identificar diferenças de qualidade, 
embora alguns estudos tivessem falhado em demonstrar uma correlação entre o vigor, o tamanho da semente e o seu desempenho em campo. Edward e Hartwig (1971), trabalhando com três linhagens isogênicas de soja, verificaram que as sementes de menor tamanho germinaram e emergiram mais rapidamente. Thomas e Costa (1996) observaram que semente de soja de menor tamanho e peso originam plântulas menos vigorosas. Entretanto, outros pesquisadores trabalhando com parâmetros idênticos, não encontraram diferenças na qualidade das sementes de diferentes tamanhos (Krzyzanowski et al., 1991; Silva Filho, 1994).

Estudo visando quantificar a preferência no tamanho de sementes de soja foi realizado por Girardi (2002), no Estado de Santa Catarina, avaliando-se quatro diferentes tamanhos com peneiras 4,5 $\mathrm{mm}$ (pequena), 5,5 $\mathrm{mm}$ (média menor), 6,5 $\mathrm{mm}$ (média maior) e 7,5 $\mathrm{mm}$ (grande), utilizando um grupo de 190 produtores de sementes. Destes, 116 agricultores ou $61,05 \%$ preferiram a semente de tamanho média menor (peneira 5,5); isso mostra, segundo o autor, uma possibilidade na economia com o uso de sementes menores. Por outro lado, $88,42 \%$ dos produtores apontaram uma preferência significativa por cultivares de soja que apresentem tamanho de sementes menores, com segurança e nível de qualidade observada e, somente $11,58 \%$ deles preferem utilizar sementes maiores, das peneiras 6,5 e 7,5 $\mathrm{mm}$.

Embora o vigor de sementes tenha sido relacionado com o tamanho de semente em alguns destes estudos, a influência do tamanho da semente no melhor estabelecimento da planta, com reflexos no rendimento, não é um assunto completamente esclarecido. O objetivo neste trabalho foi avaliar as diferenças na qualidade das sementes, no crescimento inicial das plantas, provenientes de sementes de diferentes tamanhos e seus efeitos sobre a produtividade.

\section{MATERIAL E MÉTODOS}

O experimento foi implantado na Unidade Regional do Triângulo e Alto Paranaíba (URETP), unidade da EPAMIG em Uberaba, MG. Foram utilizadas as cultivares BRSMG 752S, BRSMG 790A e BRSMG 750SRR originadas de três tamanhos de semente (peneiras 4,0 $\mathrm{mm}, 5,0 \mathrm{~mm}$ e 6,0 $\mathrm{mm}$ ), provenientes do programa de melhoramento genético da soja, parceria entre EPAMIG/Embrapa/Fundação Triângulo. A semeadura foi efetuada em 06/12/2007 em plantio direto e o desbaste foi realizado aos 21 dias após a semeadura deixando-se treze plantas por metro, com espaçamento entre fileiras de $0,50 \mathrm{~m}$. Para as avaliações de campo foram determinadas altura de plantas na colheita (cm) e produtividade (kg.ha-1 a $13 \%$ de água). A colheita manual foi realizada em $11 / 04 / 08$ e as plantas foram deixadas em galpão coberto para secar e em seguida trilhadas manualmente. Após a colheita, as sementes colhidas foram classificadas em três classes de tamanho, usando-se peneiras manuais de $6,0 \mathrm{~mm}, 6,5 \mathrm{~mm}$ e $7,0 \mathrm{~mm}$ e as análises foram conduzidas no Laboratório de Análise de Sementes da URETP/EPAMIG.

O teste de germinação foi conduzido utilizandose quatro subamostras de 50 sementes, por tratamento, semeadas em rolo de papel umedecido com água em quantidade equivalente a 2,5 vezes a massa do papel. Os rolos foram mantidos em germinador previamente regulado à $25^{\circ} \mathrm{C}$ e as avaliações seguiram os critérios estabelecidos por Brasil (1992).

$\mathrm{O}$ vigor das sementes foi avaliado por meio dos testes de envelhecimento acelerado, classificação do vigor da plântula, comprimento e massa seca de raiz. O teste de envelhecimento acelerado foi realizado com quatro subamostras de 50 sementes, colocadas sobre tela de alumínio, distribuídas em camada única em caixas plásticas contendo, no fundo, $40 \mathrm{~mL}$ de água destilada. As caixas plásticas foram tampadas e mantidas em uma incubadora regulada à temperatura constante de $41{ }^{\circ} \mathrm{C}$, durante 48 horas (Marcos Filho, 1999). Decorrido o período de envelhecimento, as sementes foram submetidas ao teste de germinação, conforme as Regras para Análise de Sementes (Brasil, 1992), efetuando-se uma única avaliação aos cinco dias, computando-se a porcentagem de plântulas normais.

Para a classificação do vigor da plântula foram utilizadas as plântulas normais provenientes do teste de germinação, avaliadas em normais fortes (vigorosas) e normais fracas (pouco vigorosas), de acordo com Nakagawa (1999).

A avaliação do desenvolvimento das raízes foi conduzida usando-se quatro subamostras de quatro sementes, semeadas em tubo PVC de $15 \mathrm{~cm}$ de diâmetro, contendo como substrato terra + areia. O sistema foi umedecido com umidade equivalente a $80 \%$ da capacidade de retenção, durante 15 dias após a semeadura, de acordo com metodologia adaptada de Sanzonowicz e Smyth (1995). O material colhido foi medido com auxílio de uma régua, em $\mathrm{mm}$, sendo o comprimento total da raiz principal a medida da ponta da raiz até a inserção do hipocótilo. Após a medição do comprimento total da raiz, o material foi colocado em sacos de papel e acondicionado em estufa a $65{ }^{\circ} \mathrm{C}$, durante 72 horas. Após este período, o material foi pesado em balança de precisão, visando à obtenção da massa seca de raiz, em gramas.

$\mathrm{O}$ experimento de campo foi conduzido utilizando o delineamento em blocos ao acaso no esquema fatorial $3 \times 3$ 
(cultivar x tamanho de semente), com quatro repetições e para as avaliações de laboratório, o delineamento inteiramente casualizado, com quatro repetições e com o arranjo dos tratamentos no esquema fatorial $3 \times 3$ (cultivar $\mathrm{x}$ tamanho de semente). Foram testadas a normalidade da distribuição dos erros e a homogeneidade da variância, fazendo-se, quando necessária, a transformação angular ou logarítmica dos valores. Os dados obtidos foram submetidos à análise de variância pelo software SAEG, utilizando-se o teste $\mathrm{F}$ e as médias foram comparadas pelo teste Tukey a $5 \%$ de probabilidade.

\section{RESULTADOS E DISCUSSÃO}

Os resultados das análises indicaram que houve interação significativa entre cultivares e peneiras para os parâmetros altura de plantas e produtividade. Observouse que a altura de plantas foi semelhante quando foram utilizadas sementes das peneiras 5,0 e $6,0 \mathrm{~mm}$. Houve redução nessa variável quando se usou sementes muito pequenas (peneira 4,0). Exceção apenas para a cultivar BRSMG 790A que não apresentou interação significativa para esse parâmetro (Figura 1). Resultados semelhantes foram constatados por Krzyzanowski et al. (2005) e Pádua et al. (2007), onde sementes maiores resultaram em plantas de soja mais altas do que as originadas de sementes menores.

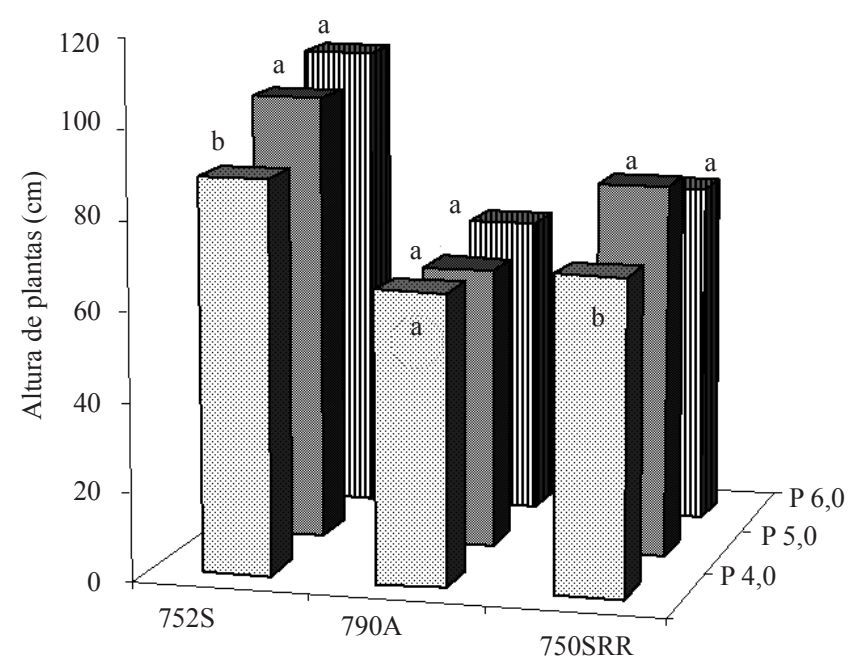

FIGURA 1. Altura de plantas (cm) de soja, cultivares BRSMG 752S (752S), BRSMG 790A (790A) e BRSMG 750SRR (750SRR), originada de diferentes tamanhos de semente. Letras minúsculas comparam peneiras dentro de cultivares, pelo teste Tukey a $5 \%$ de probabilidade.
Dentre os resultados de produtividade da cultura, foram constatadas diferenças significativas entre os resultados médios das cultivares e das peneiras. Houve relação direta entre tamanho de semente e produtividade, na qual as sementes de maior tamanho (peneiras 5,0 e 6,0) da cultivar BRSMG 752S, (peneira 6,0) da cv. BRSMG 790A e peneira 5,0 da cv. BRSMG 750SRR produziram mais (Figura 2). Krzyzanowski et al. (2005), trabalhando com quatro cultivares de soja e quatro tamanhos de sementes, também verificaram resultados semelhantes. Os autores concluíram que há um efeito benéfico do tamanho da semente na produtividade da soja, ou seja, quanto maior o tamanho melhor rendimento da cultura. Ainda pela Figura 2, para a cultivar transgênica BRSMG 750SRR, não foi verificado o mesmo comportamento, sendo a maior produtividade observada nas sementes originadas da peneira 5,0 $\mathrm{mm}$. Por outro lado, Lima e Carmona (1999) avaliando quatro cultivares de soja e três tamanhos de sementes, constataram que o tamanho não afeta o desempenho em campo, em termos de população de plantas, altura, número de vagens e produtividade.



FIGURA 2. Produtividade (kg.ha-1) de soja, cultivares BRSMG 752S (752S), BRSMG 790A (790A) e BRSMG 750SRR (750SRR), originada de diferentes tamanhos de semente. Letras minúsculas comparam peneiras dentro de cultivares, pelo teste Tukey a $5 \%$ de probabilidade.

Pelos resultados observados, a semeadura realizada com sementes menores produz plantas com menor altura na colheita e menor potencial de produtividade, em relação às sementes maiores. Embora as três cultivares avaliadas não apresentassem o mesmo comportamento, pode-se supor 
que em condições ambientais desfavoráveis, a semente de maior tamanho, que geralmente possui maior quantidade de reserva, exercerá papel importante no estabelecimento e no rendimento da lavoura.

Nas avaliações de laboratório, os resultados da análise de variância revelaram que houve efeito significativo na interação dos fatores cultivar e peneira sobre a germinação e o comprimento de raiz. Nos demais testes, envelhecimento acelerado, classificação do vigor da plântula e massa seca de raiz, os resultados foram influenciados pela ação conjunta das cultivares e do tamanho das sementes.

$\mathrm{Na}$ Figura 3, são observadas diferenças de germinação entre cultivares e peneiras. Observa-se que as sementes de maior tamanho (peneira de 7,0 $\mathrm{mm}$ ) apresentaram desempenho superior nos testes de germinação, concordando com os resultados de Lima e Carmona (1997) e de Martins et al. (1997) que verificaram que o tamanho da semente afetou, de forma consistente, sua qualidade fisiológica. Entre as cultivares avaliadas, os resultados da germinação das sementes apresentaram variações. De maneira geral, com o aumento do tamanho da semente houve aumento da porcentagem de germinação, embora na cv. BRSMG 750SRR não houvesse diferença significativa entre as peneiras. No entanto, essa cultivar apresentou alta germinação em todos os tamanhos, quando comparada com as cultivares convencionais. Os melhores resultados para as três cultivares foram observados com as sementes de maior tamanho, originadas da peneira de 7,0 $\mathrm{mm}$.

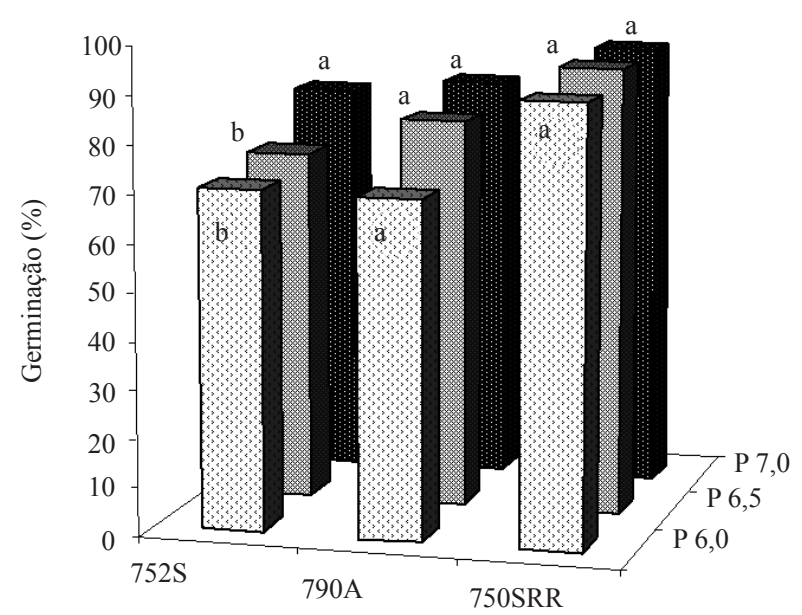

FIGURA 3. Germinação (\%) de sementes de soja, cultivares BRSMG 752S (752S), BRSMG 790A (790A) e BRSMG 750SRR (750SRR), originada de diferentes tamanhos de semente. Letras minúsculas comparam peneiras dentro de cultivares, pelo teste Tukey a $5 \%$ de probabilidade.
TABELA 1. Envelhecimento acelerado (\%), classificação do vigor da plântula (\%), em normal forte (NFOR), normal fraca (NFRA), total de plântulas normais (PLN) e massa seca de raiz (g) das cultivares BRSMG 752S, BRSMG 790A e BRSMG 750SRR, originadas de diferentes tamanhos de semente.

\begin{tabular}{lccccc}
\hline Cultivar & \multirow{2}{*}{$\begin{array}{c}\text { Env. } \\
\text { acelerado (\%) }\end{array}$} & \multicolumn{2}{c}{$\begin{array}{c}\text { Classificação do viântula }(\%) \\
\text { dFOR NFRA }\end{array}$} & $\begin{array}{c}\text { PLN } \\
\text { seca de } \\
\text { raiz (g) }\end{array}$ \\
\hline $\begin{array}{l}\text { BRSMG } \\
\text { 752S }\end{array}$ & $68,2 \mathrm{~b}$ & $43,9 \mathrm{~b}$ & $31,8 \mathrm{a}$ & $75,7 \mathrm{~b}$ & $15,4 \mathrm{a}$ \\
$\begin{array}{l}\text { BRSMG } \\
\text { 790A }\end{array}$ & $71,9 \mathrm{~b}$ & $45,0 \mathrm{~b}$ & $33,6 \mathrm{a}$ & $78,6 \mathrm{~b}$ & $10,3 \mathrm{c}$ \\
$\begin{array}{l}\text { BRSMG } \\
\text { 750SRR }\end{array}$ & $86,7 \mathrm{a}$ & $74,5 \mathrm{a}$ & $17,5 \mathrm{~b}$ & $92,0 \mathrm{a}$ & $12,3 \mathrm{~b}$ \\
\hline C.V. $(\%)$ & 9,45 & 16,03 & 33,43 & 4,91 & 9,65 \\
\hline
\end{tabular}

Médias seguidas pela mesma letra minúscula na coluna, não diferem entre si pelo teste Tukey a $5 \%$ de probabilidade.

Quanto ao vigor das sementes (Tabelas 1 e 2), avaliado pelo teste de envelhecimento acelerado, observa-se que o efeito isolado das cultivares sobre o vigor (Tabela 1) foi significativo. Martins et al. (1997) obtiveram resultados semelhantes, enquanto Lima e Carmona (1997) não observaram para as sementes pequenas, diferenças significativas entre as cultivares. Para a cultivar transgênica, assim como ocorreu no teste de germinação, foi constatado elevado vigor diferindo estatisticamente das demais, exceção para massa seca de raiz. $\mathrm{O}$ efeito do tamanho da semente sobre o vigor (Tabela 2), também foi significativo, sendo que as sementes maiores provenientes da peneira 7,0, apresentaram alto vigor quando comparadas com as da peneira $6,0 \mathrm{~mm}$.

Os resultados da avaliação de classificação do vigor das plântulas para os efeitos isolados de cultivares e de tamanhos de semente são apresentados nas Tabelas 1 e 2, respectivamente. Entre cultivares, originadas de diferentes tamanhos de semente, são observadas diferenças do vigor das plântulas com grande ênfase na cultivar transgênica (Tabela 1). Vale ressaltar, que a cultivar transgênica apresentou alta germinação e elevado vigor, pelos testes de envelhecimento acelerado e classificação do vigor de plântula, sendo que essas constatações podem constituir uma hipótese a ser confirmada. Em relação ao efeito do tamanho da semente sobre o vigor (Tabela 2), verifica-se que para plântula normal forte, não houve diferença significativa entre as peneiras. 
Entretanto, para o total de plântulas normais, as sementes maiores foram mais vigorosas do que as sementes menores (peneira 6,0 mm), confirmando os resultados encontrados pelo teste de envelhecimento acelerado.

TABELA 2. Envelhecimento acelerado (\%), classificação do vigor da plântula (\%), em normal forte (NFOR), normal fraca (NFRA), total de plântulas normais (PLN) e massa secas de raiz (g) de sementes de soja, originadas de três tamanhos de peneiras e nas cultivares avaliadas.

\begin{tabular}{cccccc}
\hline \multirow{2}{*}{ Peneira } & \multirow{2}{*}{ Env. acelerado (\%) } & \multicolumn{2}{c}{ Classificação do vigor da plântula (\%) } & \multicolumn{2}{c}{$\begin{array}{c}\text { Massa seca de } \\
\text { raiz (g) }\end{array}$} \\
\cline { 3 - 5 } & & NFOR & NFRA & PLN & $10,5 \mathrm{c}$ \\
$6,0 \mathrm{~mm}$ & $70,0 \mathrm{~b}$ & $56,5 \mathrm{a}$ & $20,9 \mathrm{~b}$ & $77,4 \mathrm{~b}$ & $12,7 \mathrm{~b}$ \\
$6,5 \mathrm{~mm}$ & $75,8 \mathrm{ab}$ & $55,5 \mathrm{a}$ & $26,8 \mathrm{ab}$ & $82,3 \mathrm{ab}$ & $14,8 \mathrm{a}$ \\
\hline $7,0 \mathrm{~mm}$ & $80,9 \mathrm{a}$ & $51,4 \mathrm{a}$ & $35,3 \mathrm{a}$ & $86,7 \mathrm{a}$ & 9,65 \\
\hline C.V. $(\%)$ & 9,45 & 16,03 & 33,43 & 4,91 & \\
\hline
\end{tabular}

Médias seguidas pela mesma letra minúscula na coluna, não diferem entre si pelo teste Tukey a 5\% de probabilidade.

$\mathrm{Na}$ avaliação do desempenho das plântulas, por meio do comprimento de raiz, a interação dos fatores cultivar e peneira foi significativa (Figura 4). Na classificação das sementes por tamanho, verifica-se que as sementes menores $(6,0 \mathrm{~mm})$ das cultivares convencionais diferiram das maiores $(7,0 \mathrm{~mm})$. No entanto, para a cultivar transgênica, embora os valores de comprimento de raiz, principalmente para as sementes de maior tamanho, fossem maiores, estes não apresentaram diferença estatística entre o das sementes menores.

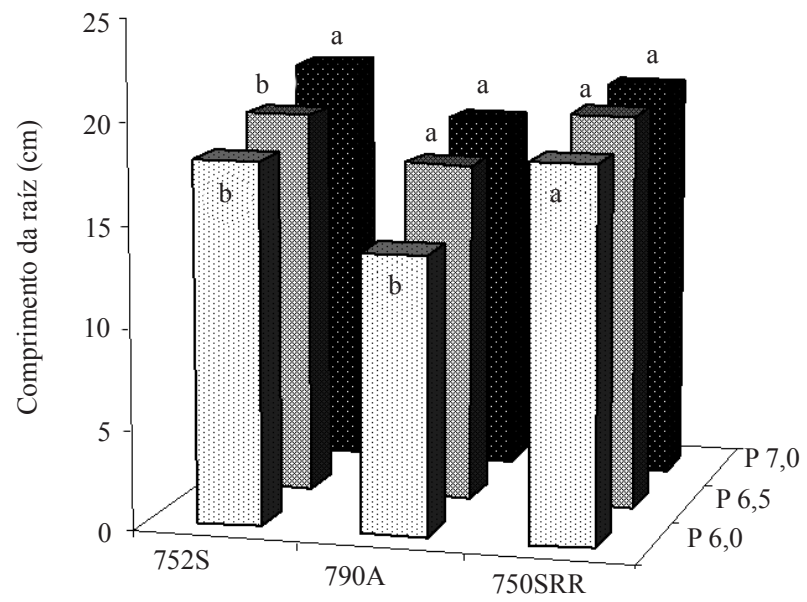

FIGURA 4. Comprimento de raiz (cm) de plântulas de soja, cultivares BRSMG $752 \mathrm{~S}$ (752S), BRSMG 790A (790A) e BRSMG 750SRR (750SRR), originado de diferentes tamanhos de semente. Letras minúsculas comparam peneiras dentro de cultivares, pelo teste Tukey a 5\% de probabilidade.
Costa et al. (2004), trabalhando com duas cultivares de soja, em três tamanhos de semente e com deficiência hídrica, observaram diferenças significativas para as sementes maiores apenas na determinação do comprimento de hipocótilo, em condição de estresse hídrico na cultivar IAC-8 e para germinação, classificação do vigor e do comprimento de raiz, sob restrição hídrica, para a cultivar IAC-22, indicando diferenças entre cultivares.

Para a variável massa seca de raiz os efeitos isolados de cultivares e de peneiras foram significativos (Tabelas 1 e 2). A cultivar BRSMG 752S apresentou o melhor desempenho, seguida da cultivar transgênica. Já a cultivar BRSMG 790A, apresentou os menores valores de massa seca de raiz, confirmando os resultados apresentados no teste de comprimento de raiz, ilustrado na Figura 4. As sementes originadas da peneira $7,0 \mathrm{~mm}$ apresentaram maior massa seca de raiz, diferindo estatisticamente das demais peneiras (Tabela 2). Cazetta et al. (1995) obtiveram resultados semelhantes com feijão, enquanto Costa et al. (2004) em soja, constataram que, na maioria dos testes de vigor utilizados, as sementes menores não diferiram das maiores. Entretanto, Beckert et al. (2000) visando avaliar o efeito da absorção de água no potencial fisiológico de semente de soja de diferentes tamanhos, concluíram que houve redução da qualidade da semente, quando a diferença no tamanho delas, em relação às de tamanho médio (peneira de 5,55 mm), para mais ou menos, é de $0,79 \mathrm{~mm}$.

\section{CONCLUSÕES}

Sementes menores (peneira 4,0 $\mathrm{mm}$ ) de soja produzem plantas com menor altura na colheita e menor produtividade, 
em relação às sementes maiores (peneira $6,0 \mathrm{~mm}$ ).

As sementes classificadas em diferentes tamanhos apresentam diferenças em qualidade fisiológica. Sementes maiores (peneira 7,0 $\mathrm{mm}$ ) apresentam maiores porcentagens de germinação e de vigor.

\section{AGRADECIMENTO}

À Fundação de Amparo à Pesquisa do Estado de Minas Gerais (FAPEMIG), pelo apoio financeiro e oportunidade de execução da pesquisa.

\section{REFERÊNCIAS}

BECKERT, O.P.; MIGUEL, M.H.; MARCOS FILHO, J. Absorção de água e potencial fisiológico em sementes de soja de diferentes tamanhos. Scientia Agrícola, v.57, n.3, p.671675,2000 .

BRASIL. Ministério da Agricultura, Pecuária e Abastecimento. Regras para análise de sementes. Ministério da Agricultura, Pecuária e Abastecimento. Secretaria de Defesa Agropecuária. Brasília, DF: Mapa/ACS, 2009. 395p.

CARVALHO, N.M.; NAKAGAWA, J. Sementes: ciência, tecnologia e produção. 4.ed. Jaboticabal: FUNEP, 2000, $588 \mathrm{p}$.

CAZETTA, J.O.; SADER, R.; IKEDA, M. Efeito do tamanho no desempenho germinativo de sementes de feijoeiro (Phaseolus vulgaris L.). Científica, v.23, n.1, p.65-71, 1995.

COSTA, P.R.; CUSTÓDIO, C.C.; MACHADO NETO, N.B.; MARUBAYASHI, O.M. Estresse hídrico induzido por manitol em sementes de soja de diferentes tamanhos. Revista Brasileira de Sementes, v.26, n.1, p.105-113, 2004.

EDWARD JR. C.J.; HARTWIG, E.E. Effect of seed size upon rate of germination in soybeans. Agronomy Journal, v.63, p.429-430, 1971.

GIRARDI, R.E. Estratégias de marketing no agronegócio de semente de soja. 2002. 124f. Dissertação (Mestrado em Engenharia de Produção) - Universidade Federal de Santa Catarina, Florianópolis. 2002.

HAIG, D.; WESTOBY, M. Seed size, pollination casts and angiosperm success. Evolutionary Ecology, v.5, p.231-247, 1991.

KHAH, E.M.; ROBERTS, E.H.; ELLIS, R.H. Effects of seed ageing on growth and yield of spring wheat at different plantpopulation densities. Field Crops Research, v.20, p.175-190, 1989.
KOLCHINSKI, E.M.; SCHUCH, L.O.B.; PESKE, S.T. Crescimento inicial de soja em função do vigor das sementes. Revista Brasileira de Agrociência, v.12, n.2, p.163-166, 2006.

KRZYZANOWSKI, F.C.; FRANÇA NETO, J.B.; COSTA, N.P. Efeito da classificação de sementes de soja por tamanho sobre sua qualidade e a precisão de semeadura. Revista Brasileira de Sementes, v.13, p.59-68, 1991.

KRZYZANOWSKI, F.C.; FRANÇA NETO, J.B.; COSTA, N.P. da; HENNING, A.A.; VIEIRA, B.G.T.L. Influência do tamanho da semente na produtividade da cultura da soja. In: REUNIÃO DE PESQUISA DE SOJA DA REGIÃ̃O CENTRAL DO BRASIL, 27., Cornélio Procópio, 2005. Resumos... Londrina: Embrapa Soja. p.567-568.

LIMA, A.M.M.P.; CARMONA, R. Padronização por tamanho de sementes de soja na qualidade e desempenho em campo. In: CONGRESSO BRASILEIRO DE SEMENTES, 10, Foz do Iguaçu, 1997. Informativo ABRATES, v.7, n.1/2, p.58, 1997.

LIMA, A.M.M.P.; CARMONA, R. Influência do tamanho da semente no desempenho produtivo da soja. Revista Brasileira de Sementes, v.21, n.1, p.157-163, 1999.

MARTINS, C.A.O; PADILHA, L.; FERREIRA, A.C.B.; MANTOVANI-ALVARENGA, M.; DIAS, D.C.F.S. Influência da classificação por tamanho na germinação e no vigor de sementes de soja (Glycine Max (L.) Merrill). 1997. Informativo ABRATES, v.7, n.1/2, p.52, 1997.

MARCOS FILHO, J. Teste de envelhecimento acelerado. In: KRZYZANOWSKI, F.C.; VIEIRA, R.D.; FRANÇA NETO, J.B. (Ed.). Vigor de sementes: conceitos e testes. Londrina: ABRATES, 1999. cap.3.1, p.3.24.

MUNIZZI, A; BRACCINI.; A.L.; RANGEL, MA. S; SCAPIM; CA; ALBRECHT, L.P. Qualidade de sementes de quatro cultivares de soja, colhidas em dois locais no estado de Mato Grosso do Sul. Revista Brasileira de Sementes: v.32, n.1, p.176-185, 2010.

NAKAGAWA, J. Testes de vigor baseados no desempenho das plântulas. In: KRZYZANOWSKI, F.C.; VIEIRA, R.D.; FRANÇA NETO, J.B. (Ed.). Vigor de sementes: conceitos e testes. Londrina: ABRATES, 1999. cap.2.1, p.2.24.

PÁDUA, G.P.; FRANÇA NETO, J.B.; COSTA, O.; ZITO, R.K.; KRZYZANOWSKI, F.C.; GAZZIERO, D.L.P. Aplicação de glyphosate como dessecante em précolheita em semente de soja: efeito sobre a produtividade. In: REUNIÃO DE PESQUISA DE SOJA DA REGIÃO CENTRAL DO BRASIL, 29, Campo Grande, MS. 2007. Resumos... Londrina: Embrapa Soja, 2007. p.225-227. (Documentos, 287). 
SANZONOWICZ, C.; SMYTH, T.J. Effect of hydrogen on soybean root growth in a subsurface solution. Pesquisa Agropecuária Brasileira, v.30, n.2, p.255-261, 1995.

SCHUCH, L.O.B. Vigor das sementes e aspectos da fisiologia da produção em aveia-preta (Avena strigosa Schreb.). 1999. 127f. Tese (Doutorado em Ciência e Tecnologia de Sementes) - Faculdade de Agronomia "Eliseu Maciel" - Universidade Federal de Pelotas. 1999.

SCHUCH, L.O.B.; NEDEL, J.L.; ASSIS, F.N. Crescimento em laboratório de plântulas de aveia-preta (Avena strigosa Schreb.) em função do vigor das sementes. Revista Brasileira de Sementes, v.21, n.1, p.229-234, 1999.

SIDDIQUE, K.H.M.; TENNAT, D.; PERRY, M.W. Water use and water use efficiency of old nad modern wheat cultivars in a mediterranean-type environment. Australian Journal of Agriculture Research, v.44, p.431-447, 1990.
SILVA, W.R.; MARCOS FILHO, J. Influência do peso e do tamanho das sementes de milho sobre o desempenho no campo. Pesquisa Agropecuária Brasileira, v.17, n.5, p.1743-1750, 1982.

SILVA FILHO, P.M. Desempenho de plantas e sementes de soja classificadas por tamanho e densidade. 1994. 64f. Dissertação (Mestrado em Ciência e Tecnologia de Sementes) Faculdade de Agronomia Eliseu Maciel, Universidade Federal de Pelotas, Pelotas.

TEKRONY, D.M.; EGLI, D.B. Relationship of seed vigor to crop yield: A review. Crop Science, v.31, p.816-822, 1991.

THOMAS, A.L.; COSTA, J.A. Influência do déficit hídrico sobre o tamanho das sementes e vigor das plântulas de soja. Pesquisa Agropecuária Gaúcha, v.2, p.57-61, 1996.

VANZOLINI, S.; CARVALHO, N.M. Efeito do vigor de sementes de soja sobre o seu desempenho em campo. Revista Brasileira de Sementes, v.24, n.1, p.33-41, 2002. 